University of New Hampshire

University of New Hampshire Scholars' Repository

\title{
Towards Data Literacy Competencies: business students, workforce needs, and the role of the librarian
}

Wendy G. Pothier

University of New Hampshire, Durham, wendy.pothier@unh.edu

Patricia B. Condon

University of New Hampshire, Durham, patricia.condon@unh.edu

Follow this and additional works at: https://scholars.unh.edu/library_pub

Part of the Library and Information Science Commons

\section{Comments}

This is an Accepted Manuscript of an article published by Taylor \& Francis in the Journal of Business \& Finance

Librarianship on October 21, 2019, available online: https://www.tandfonline.com/doi/full/10.1080/

08963568.2019 .1680189

\section{Recommended Citation}

Pothier, Wendy G. and Condon, Patricia B., "Towards Data Literacy Competencies: business students, workforce needs, and the role of the librarian" (2019). University Library Scholarship. 119.

https://scholars.unh.edu/library_pub/119

This Article is brought to you for free and open access by the University Library at University of New Hampshire Scholars' Repository. It has been accepted for inclusion in University Library Scholarship by an authorized administrator of University of New Hampshire Scholars' Repository. For more information, please contact Scholarly.Communication@unh.edu. 
This is an Accepted Manuscript of an article published by Taylor \& Francis in the Journal of Business \& Finance Librarianship on October 21, 2019, available online: https://www.tandfonline.com/doi/full/10.1080/08963568.2019.1680189

Towards Data Literacy Competencies: business students, workforce needs, and the role of the librarian

Wendy Girven Pothier* and Patricia B. Condon

*Corresponding Author contact: wendy.pothier@unh.edu

Wendy Girven Pothier is Business Librarian at the University of New Hampshire, Durham, NH, USA. https://orcid.org/0000-0002-9358-9293

Patricia B. Condon, PhD is Research Data Librarian at the University of New Hampshire, Durham, NH, USA. https://orcid.org/0000-0003-3242-6666

\begin{abstract}
Companies are looking to harness the power of data, both big and small, to take their business to new levels. One major hurdle for companies seeking to become data-centric is facing a lack of data literate talent for hire in the current market of recent college graduates. This article establishes a conversation about data literacy in business education, discusses the role of the librarian in this work, and proposes a set of data literacy competencies that librarians could help incorporate into business school education, as has been similarly seen in other disciplines.
\end{abstract}

Keywords: Data Literacy, Business Librarianship, Academic Libraries, Big Data, Business

Word count: 9422 


\section{Introduction}

Data is a valuable and powerful business asset. Organizations are striving to be data centric collecting and maintaining data about their operations, customers, competitors, and the market to help facilitate data-driven decisions. Working with and managing that data effectively prevents the loss of time, money, and opportunity, but requires employees throughout all areas of an organization to be data literate.

Data literacy skills are important for employees in all departments of a company and are not limited to data scientists, data analysis, or specialized business intelligence positions. To meet modern workforce needs, business students entering the workforce should be literate in working with data for a variety of purposes. Yet, research indicates that more training and preparation are needed in this area. However, there is limited research available as to how learning experiences for data literacy skills are integrated into business school curriculum. Insight gained from such an exploration would help libraries provide better data literacy support for business students preparing for the workplace.

This paper proposes a baseline set of data literacy competencies for all business students, regardless of what academic track within business they choose to study and aims to begin the conversation about the role of the library regarding data literacy and business school. For this paper we define data literacy as

the ability to ask and answer real-world questions from large and small data sets through an inquiry process, with consideration of ethical use of data. It is based on core practical and creative skills, with the ability to extend knowledge of specialist data handling skills according to goals. These include the abilities to select, clean, analyse, visualise, critique and interpret data, as well as to communicate stories from data and to use data as part of [decision making] (Wolff, Gooch, Montaner, Rashid, \& Kortuem, 2016, p. 23).

There is a compelling story, documented by industry needs through professional literature and reports, that illustrates the need for data literacy in the workplace beyond the specialized positions of data scientists or data analysts. Having data literate business professionals will fill organizational gaps and help to continue to move industry forward. That work needs to begin during a student's higher education experience. Simply put, we are seeking to define data literacy competencies that will help produce data-savvy business professionals, not just experts 
in data analytics, data science, or business intelligence and promote the role of librarians in this work.

First, this paper examines the goal of companies to become more data centric, outlining investments made to support this mission and the issues that impede progress in these efforts. This paper explores the gap between the need for organizations to hire talent who can fill the roles that progress them toward becoming data-centric versus the current available pool from recent college graduates. Upon establishing this key problem with modern workforce development and gaps in higher education curriculum, the paper broadly explores the role of librarians in data literacy development. After outlining previous research regarding data literacy competencies, the discussion centers on identifying seven baseline data literacy competencies that are specific to business students. From here, we address the main questions of the article: what are the data literacy skills that would make business students more successful in the workplace and what is the library's role in supporting data literacy for business students?

For this article, a combination professional literature, news stories, reports, and academic literature is appropriate, as our discussion is aimed at the intersection of the academic and business world when a student leaves the classroom and enters the workforce. Understanding workforce needs requires using non-academic literature, just as understanding the efforts made by librarians doing data literacy work requires the use of academic literature. This combination of sources highlights the two perspectives that intersect to create the problem this article addresses.

\section{Hiring for the Data-Centric Company}

Big data has evolved into a major component in business management decision making, from understanding consumer and market information to increasing efficiency in operations to improving the customer experience. Data is generated from a multitude of sources within the company and beyond, such as credit card transactions, social media, and website analytics (to name only a few). The opportunity that this data offers can allow a business to grow in numerous ways, such as by decreasing operational expenses, improving knowledge on how consumers use products, or improving how a company can capture a better share of the market by targeting their advertising. Even smaller companies have a great amount of internal data at their fingertips to 
harness. In this era, businesses have nearly limitless opportunities to become more data centric and use data as a powerful asset. However, several factors affect a business' ability to harness data such as having the technological, financial, and human resources to collect, analyze, and interpret the data. These hurdles pose big challenges for businesses wanting to take advantage of big data.

Many companies have a clear understanding of the shift that data can make in their organization and have made major investments into becoming more data centric. In the business context, datacentric connote how organizations apply "investments to capitalize on the value inherent in data as a potential driver of decisioning, messaging and superior customer experiences across all advertising and marketing functions" (Winterberry Group, 2018). According to a report by the Winterberry Group (2018), 44\% of companies surveyed intend to be "extremely" data centric by the end of 2019. This contrasts with the same report where only $9 \%$ of companies surveyed feel that they currently operate on that level. Alternatively, $30 \%$ of companies reported that they are "fairly" data centric currently, $41.5 \%$ reported that they are "somewhat" data centric, and 17\% rated themselves as "not very data centric.

The companies that are moving towards achieving their data-centric goals have largely done so in one direction: focusing on technology. Investing in technology to organize, analyze, access, and store data is an obvious and necessary step toward being a data-centric organization. Having the needed infrastructure gives a business the initial footing to accomplish the work. It is a concrete step in the right direction. However, to make the leap from "extremely" data centric from "somewhat" data centric, companies must invest in more than technology. They must invest in human resources, as well. "Many companies have invested heavily in technology as a first step toward becoming data-oriented, but this alone clearly isn't enough. Firms must become much more serious and creative about addressing the human side of data if they truly expect to derive meaningful business benefits" (Bean \& Davenport, 2019). Without a talent pool that has embraced data literacy, the technology becomes a stopping point for the organization. And in the current employment market, there is a lack of training of the human resources needed to close the gap. In a recent Gartner Trend Report, they predict "that, by 2020, $80 \%$ of organizations will initiate deliberate competency development in the field of data literacy, acknowledging their 
extreme deficiency. In addition, by $2020,50 \%$ of organizations will lack sufficient AI and data literacy skills to achieve business value" (Logan, 2018).

Data analysts and data management positions are in high demand. According to a 2016 article in Business Insider, Bentley University analyzed over 2 million job advertisements and found that data analytics is the third most sought after skill set for employers (Bort, 2016). The 2018 Winterberry Group Report echoes this need:

The most significant obstacle associated with achieving data centricity appears to be an industry-wide talent gap, particularly with respect to the analytics skills associated with data modeling, segmentation and attribution. Just $1.3 \%$ of panelists said they were "extremely confident" their organizations have the right expertise, skills and experience needed to derive value from data (down from 5.2\% in 2016) — and more than $87 \%$ of panelists said that data analytics is the competency their organization needs most to advance their use of data (Winterberry Group, 2018, slide 3).

These kinds of positions are key to seeing technological investments through to fruition. Without them, data could be left misinterpreted, unsecured, or dormant. However, a business' data needs do not solely reside with these types of positions. Data scientists have a vital role for supporting a data-centric operation, but other roles require data literacy skills to support date-related needs of an organization.

A problem area that is uncovered in surveys and reports is the lack of candidates with the desired data skills. Candidates on the job market do not have the data literacy skills to move companies in the direction where the company has already begun making an investment. There are not enough qualified candidates to fill the available positions. This lack of available talent is slowing progress of companies and is felt in areas across companies, not limited to those roles specifically tasked to work with data. Data literacy should be widespread across an organization. For example, “[Human Resource (HR)] leaders must work relentlessly to develop and recruit people who advance digital transformation across their organizations. Yet most have struggled to advance their own digital competencies. This neglect has hindered their ability to leverage data into talent strategies that can help transform their businesses" (Sinair, Ray, \& Canwell, 2018). HR metrics could help companies find and recruit top candidates, ultimately helping a company 
execute their business strategy. This is one example of the need for more data literacy across an organization. Another example touches on those working in marketing:

Perhaps the most significant challenge facing data users in the comparatively mature U.S. marketplace: how to develop and nurture a corps of marketing and media professionals who embed certain fundamental data skillsets - predictive analytics, segmentation and modeling, for example — as part of their essential toolset, rather than as a specialized capability (Winterberry Group, 2018, slide 28).

While there is an increase in higher education programs and certificates for data analytics, particularly for online learners (Public Affairs, UC Berkley, 2018; "Professional Certificate in Data Science", 2019), this leaves a large gap for the many professionals working within all departments of an organization across many types of industries. Data literacy competencies are needed within many (if not most) departments in a business organization. It is not enough to educate data analysts and data scientists only, but to think more broadly about how these competencies can be learned as part of a general business education. In a recent article in Forbes, it was noted from a Wharton School of Business survey that this problem persists at both a senior leadership and early career level (Gaskell, 2018). Inserting data literacy competencies into the curriculum will help companies overcome their hiring hurdles and address the skillset required in the modern business environment.

\section{Disparate Perceptions: Employers vs. Recent Grads}

There is a general trend today that shows a marked difference of opinion between employers and recent college graduates who they employ in terms of both skill level and job preparation. The difference in opinion creates a preparedness paradox for employers, recent grads, and educators. The sentiment is articulated in surveys by Payscale and the National Association of Colleges and Employers, both which indicate a large disparity between employer and new graduates' perceptions of workplace competencies (Bauer-Wolf, 2018; Strauss, 2016). This translates broadly over many skill area, but also reflects specifically in the area of data literacy. Strauss reports that the Payscale survey indicated that out of over 63,000 managers surveyed, 36\% reported that new grad hires were lacking in their data analysis skills, including using Excel, Tableau, R, etc. (Strauss, 2016). 
Survey data shows that MBA students are eager to learn data skills and expect their curriculum to reflect this desire. In 2018, a survey of MBA applicants indicated that 97 percent expected to learn "a moderate amount" or "a lot" or "a great deal" of data analytics skills in their respective programs, which they identified as a needed skill to understand how organizations could better leverage data (QS Top MBA, 2018). However, a survey of the top MBA programs in the United States and United Kingdom indicated minimal dedicated learning opportunities for data topics. In a survey of over 160 courses at 16 prestigious MBA programs, two-thirds of programs required a course in data science, but only one of those programs required more than two. Additionally, while one school offered more than 30 courses in data science, most had less than 10 courses in this area (Gaskin, 2018). Beyond data science, Stanford University offered a course in Data, Learning and Decision Making and Data Decision Making; Northwestern offered a course in Data Analytics Decisions; and New York University offered courses in Dealing with Data and Data-Driven Decisions (Gaskin, 2018). These courses are examples in MBA curriculum that address data needs; although, most are offered as electives and are not offered regularly. While most schools surveyed had data-related course requirement, many offer a course on statistics to meet that requirement (Gaskin, 2018).

When it comes to undergraduate business education, $65 \%$ of both business decision-makers and corporate recruiters express a preference to hire recent grads with "industry specific skills who may be slower to advance later on, rather than the liberal arts graduate who needs to be trained" (Bentley University, 2014). However, few students have the skills through their coursework required to accomplish the jobs. A 2017 article highlighting the findings of the Business-Higher Education Forum report, indicated that over 2.72 million new jobs will appear in 2020 that seek workers with data analytics skills, which has increased from 2.35 million in 2015 (Fain, 2017). Those job opportunities are in contrast with the opportunities recent graduates obtained for their programs, as noted in this Gallup poll:

69 percent of employers expect candidates with data science skills will get preference for jobs with their organizations. But just 23 percent of college leaders said their graduates will have those skills. One reason for this gap is "an educational culture where both faculty and students devote little time outside of their own specialties," the report said. So 
while data scientists with graduate degrees have the chops, business majors typically do not (Fain, 2017).

Likewise, employers have not changed their hiring practices to adequately respond to the disconnect. "The time-honored practice of treating degrees as proxies for skill sets doesn't work with data science and data analytics," the report said (Fain, 2017). With this consideration, finding ways to incorporate competency-based data literacy skills into business education is a pro-active way to support student success as they seek employment beyond graduation.

\section{Extant data literacy competencies}

From the professional literature, we have illustrated an increase in discussions about the importance of data in business operations and need for data literate employees. In the academic literature, this emphasis is on research data and requisite data literacy education for researchers (Koltay, 2017). Data literacy has emerged as a distinct skillset for mastery with roots in media literacy, visual literacy, scientific literacy, and statistical literacy (Koltay, 2015; Carlson, Fosmire, Miller, \& Nelson, 2011). However, the concept of data literacy - how it is defined and what skills are fundamental - is not yet standardized and we can see this in the variety of terms and definitions used to describe it (Koltay, 2015; Wolff et al., 2016). In the literature we find data information literacy (Carlson et al., 2011), research data literacy (Schneider, 2013), and science data literacy each approached with a different audience and perspective in mind. Wolff et al. (2016) point out that "it is clear that [the terms and definitions] each have a different focus which tends to reflect the context in which it was derived" (p. 11). This same contextualization is evident in efforts to identify data literacy competencies.

In the past ten years, there has been considerable effort to define data literacy competencies for undergraduate and graduate researchers. The bulk of this work is coming from the library and information science fields (Calzada Prado \& Marzal, 2013; Carlson et al., 2011; Risdale et al., 2015; Schneider, 2013). Data literacy is at home in the library and information science fields because it is complementary to information literacy. In fact, most of the attempts to characterize data literacy competencies have either synthesized previous efforts to identify data literacy competencies or generated competencies that align with principles from the Association of 
College and Research Libraries' (ACRL) Information Literacy Competency Standards for Higher Education (2000).

While the extant data literacy competencies tend to correspond well with each other, they are unique in how they originated and how they are presented. Schneider (2013) devised eight broad research data literacy concepts that align the ACRL Information Literacy Competency Standards for Higher Education with the Library of Congress' Digital Preservation Outreach and Education curriculum model, squarely placing data literacy within the digital curation and data management conversation. The aim of this set of competencies was to provide a matrix for curriculum building that could scale to different levels of data needs. Calzada Prado \& Marzal (2013) developed a framework of five core data literacy competencies generated from synthesizing related competency lists and structuring it to complement the information literacy standards. Their framework is broad, intended to be universal and adaptable to multiple disciplines. The goal of the competencies provided by Calzada Prado \& Marzal was to define "an understructure on which learning experiences can be built."

Other data literacy competency models have been more comprehensive. For example, one of the earliest efforts led to the Data Information Literacy Project, an Institute of Museum and Library Services (IMLS) grant-funded collaborative project involving libraries at the University of Michigan, University of Minnesota, Purdue University, and Cornell University (http://www.datainfolit.org/). Grant partners identified twelve data information literacy competencies from faculty interviews and student assessments and explored the roles of librarians in teaching those competencies (Carlson et al., 2011; Carlson, Johnston, Westra, \& Nichols, 2013; Carlson, Sapp Nelson, Johnston, \& Koshoffer, 2015). While the researchers encouraged broad application, the competencies emerged from an e-science perspective and are tailored to scientific research. Probably the most comprehensive set of competencies was created by a group from Dalhousie University, who conducted a review of the literature and synthesized the findings into a data literacy matrix, which outlines key knowledge areas that include core, conceptual, and advanced competencies and associated skills (Risdale et al., 2015). The goal was to identify a structure for creating learning outcomes and assessing data literacy skills. For a comparison of these data literacy competencies, see Table I. 


\section{[Insert Table I near here]}

While the literature often focuses on a well-defined audience for data literacy in graduate and post-graduate researchers, attention has also focused on translating data literacy competencies to accommodate undergraduate students who may require baseline skills for undergraduate research, entering graduate school, or entering the workforce (Shorish, 2015; Zilinski, Sapp Nelson, \& Van Epps, 2014). Shorish (2015) notes that

Data information literacy skills are relevant even if students do not go on to advanced degrees. The majority of individuals receiving postsecondary education in the United States seek a bachelor's degree as their terminal degree. Moreover, these skills are critical to most aspects of business today (p. 102).

Zilinski et al. (2014) translated competencies from the Data Information Literacy Project into competencies that were appropriate for undergraduate students. From this modified list, the authors created the Data Credibility Checklist, an instructional tool for introducing data literacy concepts to undergraduates. Taking a broader approach to data literacy education, Sapp Nelson (2015), created a pilot competency matrix designed to provide a framework for scaffolding data literacy instruction across undergraduate courses for improved curriculum building and sustainable data literacy programs.

The extant data literacy competencies have largely emerged with a focus on the sciences. Because of the landscape of research data management and data sharing in higher education over the past ten years, this is not surprising. However, data literacy needs in some academic and professional areas, such as the arts and business, have not been as clearly detailed. While some competencies are universal and others broad enough to be interpreted in multiple contexts, customizing competencies to different contexts is not always obvious. This is the case for business students who will likely work heavily with proprietary data and use both data and statistics to communicate changes and new directions. The bottom line for business students is better business, not better science, but both are accomplished with integrity, respect for the underlying data, and an understanding of the broader impacts of data handling. 
There has been some interest in data literacy for business students, although it has not yet been broadly developed. A syllabi review of Eastern Michigan University College of Business (Brodsky, 2017) found that across all departments, data was, in fact, being used in courses; however, the level of engagement with data varied. The author concluded that $62 \%$ of courses would directly benefit from data literacy instruction but that different courses required different sets of competencies to be taught. There is also some indication of data literacy needs in a 2003 mapping of business student information needs with the Information Literacy Competency Standards (Cunningham, 2003). The author highlighted "is able to identify the sources of public company financial data" and "is able to transfer financial or other data to Excel or other spreadsheet software for further analysis or data manipulation.” More recently, Macy and Coates (2016) mapped Calzada Prado and Marzal's (2013) data literacy competencies to the National Standards for Business Education and results from an Association of American Colleges \& Universities survey of employer needs. They drafted student learning outcomes supporting these competencies and, working with business faculty, designed a workshop for business students to help develop these skills.

However, for business programs, most of the research appears to come from business faculty and looks at incorporating skills that support data science, data analytics, and business intelligence through redesigning curriculum or offering new areas of concentration rather than integrating data literacy competencies throughout the curriculum (Gupta, Goul, \& Dinter, 2015; Horton, Baumer, \& Wickman, 2015; Pan et al., 2018; Wilder \& Ozgur, 2015). For example, Pan et al. (2018) surveyed industry partners to identify priority skills needed in the workforce that are missing from the business curriculum. The authors conducted the survey to inform their revisions of existing courses to include data analytics learning objectives for non-analytics business majors. However, in 2018, Gartner published a Trend Insight Report surveying Chief Data Officers about the major challenges facing their organizations. Respondents "listed 'poor data literacy' as the second highest internal roadblock to success, behind 'culture challenges to accept change' and just ahead of 'lack of relevant skills or staff'" (p. 6). The report argues that “A sustained data literacy program addresses all three of these roadblocks" (Logan \& Duncan, 2018). 


\section{Data literacy competencies for business students}

As discussed in previous sections, employers want new hires to have strong data literacy skills and students anticipate learning these skills in class, but business schools struggle to keep pace with both student and employer expectations. One way to address the need for data skills has been to add data analytics and data science courses and concentrations into business education programs. However, not all business school graduates need to be data scientists or proficient in data analytics. Business students need a foundational understanding of data and how data is used in a business context, from human resources to marketing to management to advertising.

Wolff et al. (2016) identified four categories of data literate citizens based on the level of skill and understanding required to complete tasks using data. While the authors acknowledge that these categories are not exhaustive, the categories provide a framework for conveying the varying depths of skill required by individuals based on the extent to which they engage with data. Communicators tell "stories from data"; readers "critique and interpret data"; makers "ask and answer real-world questions" and "use data as part of [decision making]"; and scientists "combine strong technical data skills with communication skills and in-depth knowledge of the domain of the data" (Wolff et al., 2016, pp.18-23). These categories can be employed to address the varying levels of skills required by business students and highlight the baseline competencies that would enable a more data-centric approach to all areas of an organization.

Extrapolating from extant data literacy competency frameworks, we identified competencies that we consider to be most pressing for business students. This is not an exhaustive list and it is not a final list; this is the beginning of a discussion. It is a discussion between data librarians and business librarians as we refine how data literacy competencies can be addressed and applied more broadly. It is a discussion between business faculty and librarians about outlining data literacy competencies for business students and designing learning experiences for integrating those competencies into curriculum. It is a discussion about workforce needs and how librarians can help students prepare themselves for the modern job market.

We identified seven key business data literacy competencies which would help students become data literate employees:

1. Data organization and storage

2. Understanding data used in business contexts 
3. Evaluating the quality of data sources

4. Interpreting data

5. Data-driven decision making

6. Communicating and presenting effectively with data

7. Data ethics and security

\section{Data organization and storage}

Basic data management competencies are essential for all business students. For purposes of business continuity, data organization and storage are very important. New personnel are hired, departments collaborate across the company to complete large projects, and deadlines must be met, all while revenue is at stake. Throughout this, data must be accessible, shared, and understood without interruption because chaotic file structures cost time and money.

Organizing data is a foundational data management skill that focuses on logical folder structures, consistent file naming conventions, and version control. Effective data organization is essential for finding and retrieving files, collaborating and sharing files, and helping maintain adequate control over files to prevent loss or accidental disclosure. Many businesses will use a data asset management system, but basic organization skills are still essential even when implementing a tool that support organizing, finding, and retrieving files.

Foundational data management skills differ from database management and organization, a more specialized skillset involving designing and implementing high-quality databases. In their survey of the Samford University Business School advisory boards, Pan et al. (2018) found that $14 \%$ of respondents identified database management as a skill beyond what is expected of an undergraduate business students, $38 \%$ identified it as a required skill, and $48 \%$ identified it as only important for data analytics minors. While a general understanding of database structure, function, and use is important for effective communication between business professionals and information technology or analysis professionals, not all business students are expected to possess advanced database management skills. 
While managing secure storage and implementing effective backup solutions it is often the purview of information technology (IT) professionals, everyone has a responsibility in this domain. Secure storage and backup play a role in sharing data within a company, preventing data breaches from outside the company, and avoiding accidently loss of data through technology failure or human error. One aspect of an individual's responsibility may be to ensure that files are stored on shared drives for access by other team members or for automated backup by IT. The practical awareness of the consequences of poorly secured, poorly backed-up data empowers individuals to be better stewards of their digital information.

\section{Understanding data used in business contexts}

While data may be used differently in workplace contexts than in pure research and academic scholarship pursuits, understanding the sources, uses, and applications of data is a universal competency. Calzada Prado \& Marzal (2013) describe this competency as the "need to know what is meant by data and be aware of the various possible types of data" (p. 130). The Australian Bureau of Statistics (2010) described this competency as data awareness and it addresses questions such as: Are the data relevant and appropriate? Where did the data come from? How were the data collected? Are the data fit for purpose? For business students, this competency prepares them to think critically about the statistics that they are commonly called upon to use. With an emphasis on becoming data centric, it would be helpful for employees (and therefore business students who want to become employees) to understand what types of data exist within or are accessible to an organization, where it comes from, and how it used within the organization.

Business students need to focus on what kinds of data are used for daily operations within a business and what data is generated through those operations. This competency is foundational for the data-driven decision-making competency. As mentioned previously, MBA candidates expected to learn data skills in their course work to understand how data would leverage business decisions. They expect to learn the context and availability of data within an organization to be able to understand its potential applications within the company. Business students need to understand the underlying data that is being used to drive decisions in areas such as where to invest personnel and resources. They need to understand how data has been or can be collected, the types of data available, and the applications and limitations of the data they are using. 


\section{Evaluating the quality of data sources}

Each of the data literacy competency frameworks that we looked at included some variation of evaluation of data. Risdale et al. (2015) associated this competency with the ability to "critically assesses sources of data for trustworthiness" (p. 38). Calzada Prado \& Marzal (2013) focused on applying evaluation criteria such as authorship, methods of collection and analysis, and interpretation. Carlson et al. (2011) expressed the evaluation of data as quality assurance focusing on the accuracy, consistency, and integrity of data collected or compiled. The authors go on to explained that "[Q]uality assurance is facilitated or disrupted by the quality of documentation (annotation/metadata) produced, and the organizational schema, or lack thereof, of a given data set" (p. 643).

Schneider (2013), on the other hand, interpreted the evaluation of data as the appraisal of data for long-term value and retention. This becomes an important competency when considering electronic records management, the period of retention required for certain types of documents, and maintenance of a reasonably sized document library.

This competency qualifies business students to evaluate data for reuse and assess underlying data sources of statistics for quality, credibility, and trustworthiness. Evaluating the quality of data sources sets the foundation for interpreting data, data-driven decision making, and data ethics, all of which rely on high quality, trustworthy data to support work in an organization. This competency also directly relates to statistical literacy. Statistical literacy "is the ability to accurately understand, interpret and evaluate the data that inform these issues" (Australian Bureau of Statistics, 2010).

\section{Interpreting data}

Using data effectively requires recognizing what analyzed and processed data means by interpreting the results that you have found or have been presented, which can have many implementations in the workplace. Risdale et al. (2015) include two competencies related to identifying problems with data and data interpretation. Knowledge associated with these competencies include identifying "key take-away points and integrates this with other important information" and using "data to identify problems in practical situations" and grand challenges (p. 38). 
Learning how to interpret data prepares business processionals for recommending actions based on the data analysis or making data-driven decisions. "What looks useful to data scientists will most likely mean nothing to a sales executive and vice versa. However, both parties have much to gain from data (Kaplan, 2019)." While it is not always the same individual who both analyzes the data and explains what that analysis means, in order to be effective at interpreting data, business professionals also must understand the data and the type of analysis that was completed on it.

\section{Data-driven decision-making}

Data-driven. Surrounded with the buzz of big data, we hear the term data-driven everywhere: data-driven initiatives, data-driven innovations, data-driven society, data-driven economy. Datasavvy business professionals can evaluate findings from data analysis and apply them to make decisions about actions to take or directions to follow. Risdale et al. (2013) connects this competency with the following tasks:

- Prioritizes information garnered from data

- Converts data into actionable information

- Weighs the merit and impacts of possible solutions/decisions

- Implements decisions/solutions (p. 38)

This competency speaks clearly to the management side of business and the need for leadership to understand the impact of data on the decision-making process. This can be for both large- and small-scale decisions within an organization, as well as helping those who gather and present the data to understand its organizational impact. It is also important to note that achieving this competency requires an understanding of the competencies listed prior to it.

\section{Communicating and presenting effectively with data}

Effectively communicating stories from data requires business professionals to convey complex concepts to diverse audiences who have varying familiarly with the subject and different desired outcomes. Risdale et al. (2013) relates several competencies to tasks associated with communicating data effectively and presenting with data effectively. In particular, the authors 
include a competency that focuses on presenting data verbally specifically about crafting and delivering meaningful, coherent, and appropriate presentations with cogent arguments.

This competency includes skills associated with visual literacy and working with visual representations of data. Visual literacy is defined as "the ability to interpret images as well as to generate images for communicating ideas and concepts" (Stokes, 2001, p. 10). Carlson et al. (2011) describe a data visualization and representation competency as avoiding "misleading or ambiguous representations when presenting data" and understanding "the advantages of different types of visualization, for example, maps, graphs, animations, or videos, when displaying data" (p. 653). Risdale et al (2013) further describe the data visualization competency to include critically assessing "graphical representations for accuracy and misrepresentation of data" (p. $38)$.

Employers are looking for new hires who come with polished soft skills (Bauer-Wolf, 2019). Understanding how to read, create, use, and present meaningful and effective visual representations of data and to provide a clear and coherent narrative about the data falls into this qualification.

\section{Data ethics}

News stories about data breaches and issues around data security, online privacy, ethically questionable collection and use of data have become commonplace (for example: Barbaschow, 2019; Whittaker, 2019a; Whittaker, 2019b; Verma, 2014). The many challenges associated with working with digital data in a networked and online environment continue to plague businesses. It is not enough for business students to understand data, how to apply findings, and how to communicate with it effectively. Underpinning all of the data literacy competencies is a responsibility to approach collection, interpretation, use, and security of data ethically and with integrity.

The principles of data ethics are built on data ownership, intellectual property rights, appropriate attribution and citation, and confidentiality and privacy issues involving human subjects (Carlson et al. 2011). Calzada Prado \& Marzal (2013) speak to the essence of this competency as the "need to be aware of the role of data in society, how they are generated and by whom, and their 
possible applications, as well as the implications of their use" (p. 130). Just because you can get access to data does not necessarily mean that you have permission to use those data - it does not mean that they are public data or that the collection of the data was done with the consent of the people providing the data. Just because you can use data, does not mean that you should - the data may be biased depending on how it was collected or by whom, or the implications of its use may have unwarranted societal impact.

Well-equipped business professionals need to be able to navigate complex data ethics questions and understand the importance of data security. Lack of knowledge in this area, or infringements on data privacy and security, impact the reputation and public trust of companies.

\section{Integrating data literacy competencies into the curriculum: librarian role}

Having established both the demonstrated need for business students to be data literate as well as outlining baseline competancies that we recommend be part of the cirriculum during their coursework in business school, we look to the role that librarians can play in integrating the competancies into the classroom and cirriculum. The concept of information literacy has long been associated with the work of academic librarians and is incorporated most commonly through the Framework for Information Literacy for Higher Education published by Association of Collecge and Research Libraries (ACRL) (2015). More recently, other literacies have received attention from librarians including digital literacy, visual literacy, and data literacy. These other literacies do not have authoritative mapped standards and typically rely on loosely-defined core competancies for application.

The work of the Data Information Literacy Project resulted in the Developing Data Information Literacy Program: A Guide for Academic Librarians. The emphasis of this guide is how librarians can work with faculty and graduate students to develop a program that is assessable and sustainable. This guide looks at the librarian as a key player to creating the program because "many academic librarians have a broad understanding of scholarship in general and an in-depth understanding of disciplinary best practices in scholarly communication. Librarians also have the ability to identify and recommend resources, tools, and even skills that researchers need but may not be aware of" (Wright et al, 2015). 
With the information literacy framework and the data information literacy project in mind, it is strategic for librarian to take a lead role in data literacy instruction in the business school curriculum, both as an advocate for this work with faculty colleagues and a as purveyor of information. However, this role cannot be accomplished by a single position. Librarians, both data and business, should partner together with business school faculty to accomplish integrating data literacy into the curriculum. This following section examines the challenges of integrating data literacy competencies and some practical strategies that have been employed and can be adapted for success.

\section{Challenges}

There are several challenges for the librarian who seeks to support integrating data literacy competencies into the business school curriculum. Two potential hurdles are the difficulty of finding space in the professor's syllabi for library instruction to get facetime in the classroom with students and the complexity of integrating a broad set of baseline competencies into the various majors and programs that exist within the business discipline.

A common hurdle for any librarian-led literacy effort is to find effective ways to get classroom time with students via the faculty. As has long been established, "librarian influence on core curriculum may be limited in comparison with faculty and thus the depth of information literacy education is inappropriately marginalized by faculty and students" (Conley \& Gill, 2011). The same issue seen with information literacy instruction will likely persist with data literacy efforts, due to a lack of librarian presence with credit-bearing courses. The answer may reside in building stronger relationships with the business faculty. In efforts to work with faculty on data literacy, Sapp Nelson from Purdue University developed a Data Management Strategies SelfAssessment tool for working with junior faculty members. Conducted as an outreach workshop, this program helps new faculty members establish a relationship with librarians that focuses on data and positions librarians to further participate in the curriculum development (Carlson et al., 2015). Faculty partnerships have value, as they can help establish connections between librarians and students as well as integrate librarian expertise and literacy instruction into the content of courses. As mentioned above, collaboration between faculty and librarians is key to accomplishing the integration of data literacy competencies into the classroom. Gaining faculty 
buy-in is a crucial step and may be the first strategic direction for a librarian looking to develop this work.

With business schools offering multiple majors and degree programs, another challenge is how to integrate the data literacy competencies into a diverse curriculum that ranges from management to economics to accounting. Some might argue that the competencies are not relevant to all domains due to the nature of the work each major will take up after graduation. However, while roles will vary within an organization, these data literacy competencies serve as a baseline for all business students and would serve any employee well within an organization. This point is emphasized in the 2018 Gartner Report on Data Literacy as a Second Language, "all leaders, including HR executives, must see data literacy as a core workforce training and development priority" (Logan \& Duncan, 2018, p. 5). Baseline competencies serve as foundation knowledge for business students and employees. Other specialized knowledge regarding data, whether it is increased knowledge in data organization or data-driven decision-making would grow from this point.

\section{Opportunities}

Opportunities for successfully integrating data literacy competencies into business curricula rely on the collaboration of librarians and business faculty. The baseline competencies that we introduced can be integrated into core curricular classes, with librarians co-teaching or being embedded into the process as partners with business faculty. Each partner brings a unique perspective and awareness about this domain. For universities that have dedicated librarians for data and business, these partnerships can be comprehensive. For example, data librarians might lead the work fostering the data ethics competency, while a business librarian could focus on evaluating quality data source, while faculty member could consult with librarians on ways to more deeply embed competencies into course assignments or coordinate librarian instruction with the subject matter of the course.

There is some professional literature that details the practices of librarians developing learning experiences and integrating data literacy into the cirriculum. These examples illustrate approaches designed to address data literacy and data management skills for targeted audiences. Librarians have been working in similar spaces with information literacy for years, so 
incorporating new literacies is a natural evolution of librarian work. While most of these practical strategies have not been employed within business education, they can be modified to these contexts.

Several grant-funded projects have resulted in curriculum for data literacy. Through National Science Foundation (NSF) grant funding, Qin and D'Ignazio (2010) designed a semester-long science data literacy course focusing on STEM undergraduates with a strong focus on data management and teaching with case studies. One challenge that the researchers faced was making the case studies applicable across domains. They concluded that either a more generalized curriculum that focused on underlying concepts or the involvement of domain faculty would have improved outcomes and delivery. Through an IMLS grant, Piorun et al. (2012) created stand-alone learning modules, complete with learning objectives, case studies, and exercises, that faculty could select from and incorporate selectively into their courses. These modules also had a strong focus in data management to support student research projects and were designed to be flexible enough to accommodate undergraduate and graduate-level students.

The most relevant example in the literature of instructing data literacy for business students comes out of Indiana University-Purdue University (Macy and Coates, 2016). In cooperation with business faculty, Macy enhanced their 30-minute library instruction workshop to a 2-hour library instruction workshop focusing on data literacy competencies that directly supported the work of students toward their sophomore-year project. Importantly, Macy built in a strong assessment plan into the development of the workshop to track progress. More recently, Mendez-Carbajo, Jefferson, and Stierholz (2019) created a lesson plan that incorporated learning outcomes aligned with information literacy, quantitative literacy, and social justice using economic data about minimum wage. The authors argue that "accurate quantitative assessment of social justice issues ... must be built on a foundation of solid data literacy skills" (p. 12). The lesson is designed for introductory college courses and uses a flipped classroom style delivery.

Because of the deep connection of data literacy to workforce skill needs, digital badges or other microcredentials related to data literacy compentencies may be an opportunity for librarians to develop instruction and embed it into the business school cirriculum. Digital badges effectively demonstrate acquired skills to an employer and many employers surveyed in the context of library-related skill development were interested in the use of digital badges to demonstrate 
acquired skills (Raish \& Rimland, 2016). This is a particularly plausible way for librarians to be effective in helping to deliver content to students, as they often work outside the structure of credit bearing cirriculum and could harness badges as a way to articulate student skills outside of the traditional means of transcripts. It may also enable librarians to embed tutorials, modules, or other learning excercises directly into course content in ways beyond the common one-shot experience.

\section{Conclusion}

In this article, we described the drive for business and industry to become more data centric, the disconnect between employer data needs and the data-related skills of recent business school graduate, and previous work on defining data literacy competencies for undergraduate and graduate students. We then proposed seven data literacy competencies that we consider to be essential for business students and suggested some ways that librarians can participate in integrating these into the curriculum.

Companies recognize that becoming more data centric can take their organization to new levels and they are setting their goals and missions in accordance. Investing in technological infrastructure is one way that companies are making this effort, but the lack of employees with necessary skillsets limits the ability to fully realize their goals. This problem is wide arching across organizations and touches on all departments throughout a company, not just positions requiring data scientists or data analysts. In short, the modern business workforce requires data literacy skills. Integrating data literacy competencies into business school education would help solve the workforce issue of poorly skilled talent to fill jobs that require data-related skills. Many employers feel that recent graduates are not coming out of business school or higher education with these skills in hand. Increasing programs and certificates in data science or data analytics helps for those specialized roles, but data literacy needs to be considered more broadly and holistically for the business student.

Librarians have long been influential in integrating information literacy into curriculum and some librarians have begun to expand that work to incorporating data literacy. This work has begun in some disciplines but has not yet been widely adopted by all subject librarians. Previous efforts to define data literacy competencies have stressed the importance of implementing those 
competencies in discipline-specific environments. Focusing on tailoring data literacy competencies for business students had not been approached by business or data librarians before this discussion. Business librarians possess professional knowledge that is invaluable in conversations about defining data literacy competencies for business students and designing learning experiences for implementing those competencies.

With this article, we have initiated a call for improving data literacy skills for business students by suggesting a baseline set of data literacy competencies that librarians can help incorporate into business school curriculum. Future work in this area can focus on fostering discussions between librarians, business faculty, and employers to help refine data literacy competencies for business students, establishing a framework for scaffolding competencies to address the varies levels of skill development and need, and piloting the competency framework in core courses. 


\section{References}

Association of College and Research Libraries. (2000). Information Literacy Competency Standards for Higher Education. Retrieved from https://alair.ala.org/handle/11213/7668?show=full

Association of College and Research Libraries. (2015). Framework for Information Literacy for Higher Education. Retrieved from http://www.ala.org/acrl/standards/ilframework

Australian Bureau of Statistics. (2010, March). What Is Statistical Literacy and Why Is It Important to Be Statistically Literate? (Feature Article). Tasmanian State and Regional Indicators. Retrieved from https://www.abs.gov.au/AUSSTATS/abs@.nsf/Lookup/1307.6Feature+Article1Mar+2009\#1.\%2 0Data\%20awareness

Barbaschow, A. (2019, May 13). Over 10 million people hit in single Australian data breach: OAIC. ZDNet. Retrieved from https://www.zdnet.com/article/over-10-million-people-hit-insingle-australian-data-breach-oaic/

Bauer-Wolf, J. (2018, February 23). Overconfident Students, Dubious Employers. Inside Higher $E d$. Retrieved from https://www.insidehighered.com/news/2018/02/23/study-students-believethey-are-prepared-workplace-employers-disagree

Bauer-Wolf, J. (2019, January17). Survey: Employers Want Soft Skills for Graduates. Inside Higher Ed. Retrieved from https://www.insidehighered.com/quicktakes/2019/01/17/surveyemployers-want-soft-skills-graduates

Bean, R. \& Davenport, T.H. (2019, February 05). Companies Are Failing in Their Efforts to Become Data-Driven. Harvard Business Review. Retrieved from https://hbr.org/2019/02/companies-are-failing-in-their-efforts-to-become-data-driven

Bentley University. (2014). The PreparedU Project: An In-depth Look at Millennial Preparedness for Today's Workforce. Retrieved from https://www.slideshare.net/BentleyU/prepared-u-project-on-millennial-preparedness

Bort, J. (2016, January 23). The top 12 skills tech employers want today. Business Insider. Retrieved from https://www.businessinsider.com/12-skills-tech-employers-want-2016-1

Brodsky, M. (2017). Understanding Data Literacy Requirements for Assignments: A Business School Syllabus Study. International Journal of Librarianship, 2(1), 3-15.

Carlson, J., Fosmire, M., Miller, C. C., \& Nelson, M. S. (2011). Determining data information literacy needs: A study of students and research faculty. portal: Libraries and the Academy, $11(2), 629-657$.

Carlson, J., Johnston, L., Westra, B., \& Nichols, M. (2013). Developing an approach for data management education: A report from the data information literacy project. 
Carlson, J., Sapp Nelson, M. Johnston, L.R., \& Koshoffer, A. (2015, August/September) Developing Data Literacy Programs. Bulletin of the Association for Information Science and Technology. Retrieved from https://www.asist.org/publications/bulletin/aug-2015/developingdata-literacy-programs/

Calzada Prado, J. \& Marzal, M. Á. (2013). Incorporating data literacy into information literacy programs: Core competencies and contents. Libri, 63(2), 123-134.

Conley, T. M., \& Gil, E. L. (2011). Information literacy for undergraduate business students: examining value, relevancy, and implications for the new century. Journal of Business \& Finance Librarianship, 16(3), 213-228.

Cunningham, N.A. (2003). Information competency skills for business students. Academic BRASS 1(1). Retrieved from

http://www.ala.org/rusa/sections/brass/brasspubs/academicbrass/acadarchives/volume1number1/ academicbrassv 1

Fain, P. (2017, March 30). Data science disconnect. Insider Higher Ed. Retrieved from https://www.insidehighered.com/news/2017/03/30/report-urges-data-science-course-work-allundergraduates-close-growing-skills-gap

Gaskell, A, (2018, October 26). How data literate is your organization? Forbes. Retrieved from https://www.forbes.com/sites/adigaskell/2018/10/26/how-data-literate-is-yourorganization/\#7eb484a6355a

Gaskin, J. (2018, September 27). 16 best big data programs at prestigious MBA schools. Dataconomy. Retrieved from https://dataconomy.com/2018/09/16-best-big-data-programs-atprestigious-mba-schools/

Gupta, B., Goul, M., \& Dinter, B. (2015). Business Intelligence and Big Data in Higher Education: Status of a Multi-Year Model Curriculum Development Effort for Business School Undergraduates, MS Graduates, and MBAs. CAIS, 36, 23.

Horton, N.J., Baumer, B.S., \& Wickham, H. (2015), Setting the Stage for Data Science: Integration of Data Management Skills in Introductory and Second Courses in Statistics, CHANCE, 2840--50. Retrieved from http://chance.amstat.org/2015/04/setting-the-stage/

Kaplan, N. (2019, January 7). How to Cultivate a Data-Literate Workforce. Forbes. Retrieved from https://www.forbes.com/sites/forbestechcouncil/2019/01/07/how-to-cultivate-a-dataliterate-workforce/\#1 acbe454cfe0

Koltay, T. (2015). Data literacy: in search of a name and identity. Journal of Documentation, 71(2), 401-415.

Koltay, T. (2017). Data literacy for researchers and data librarians. Journal of Librarianship and Information Science, 49(1), 3-14.

Logan, V. (2018, February 23). Fostering data literacy and information as a second language: a Gartner trend insight report (ID: G000342240). 
Logan V. \& Duncan, A.D. (2018, November 9). Getting started with data literacy and information as a second language: a Gartner trend insight report (ID: G000352314).

Macy, K. V., \& Coates, H. L. (2016). Data information literacy instruction in business and public health: Comparative case studies. IFLA journal, 42(4), 313-327.

Mendez-Carbajo, D., Jefferson, C. O., \& Stierholz, K. L. (2019). Keeping It Real: Information Literacy, Numeracy, and Economic Data. Numeracy, 12(2), 5.

Pan, K., Blankley, A. I., Mazzei, M. J., Lohrke, C. F., Marshall, J. B., \& Carson, C. M. (2018). Surveying industry advisors to select data analytics topics for all business majors. The International Journal of Management Education, 16(3), 483-492.

Piorun, M. E., Kafel, D., Leger-Hornby, T., Najafi, S., Martin, E. R., Colombo, P., \& LaPelle, N. R. (2012). Teaching research data management: an undergraduate/graduate curriculum. Journal of eScience Librarianship, 1(1), 8.

Professional Certificate in Data Science. (2019). Retrieved from https://onlinelearning.harvard.edu/series/professional-certificate-data-science

Public Affairs, UC Berkeley. (2018, March 29). Berkeley offers its fastest-growing course - data science - online, for free. Berkeley News. Retrieved from https://news.berkeley.edu/2018/03/29/berkeley-offers-its-fastest-growing-course-data-scienceonline-for-free/

QS Top MBA. (2018). Why Data Skills Are Vital For MBA Students. Retrieved from https://www.topmba.com/blog/mba-programs-blog/why-data-skills-are-vital-mba-students

Qin, J. and D'Ignazio, J. (2010, 22 June). Lessons learned from a two-year experience in science data literacy education. International Association of Scientific and Technological University Libraries, 31st Annual Conference. Paper 5. Retrieved from http://docs.lib.purdue.edu/iatul2010/conf/day2/5

Raish, V., \& Rimland, E. (2016). Employer perceptions of critical information literacy skills and digital badges. College \& Research Libraries, 77(1), 87-113. Retrieved from https://crl.acrl.org/index.php/crl/article/view/16492/17938

Ridsdale, C., Rothwell, J., Smit, M., Ali-Hassan, H., Bliemel, M., Irvine, D., Kelley, D., Matwin, S., and Wuetherick, B. (2015). Strategies and Best Practices for Data Literacy Education: Knowledge Synthesis Report. Dalhousie University. Retrieved from http://www.mikesmit.com/wp-content/papercite-data/pdf/data_literacy.pdf

Sapp Nelson, M. R. (2017). A pilot competency matrix for data management skills: a step toward the development of systematic data information literacy programs. Journal of eScience Librarianship, 6(1), 1.

Schneider, R. (2013). Research data literacy. Communications in Computer and Information Science, 397, 134----140. 
Shorish, Y. (2015). Data information literacy and undergraduates: A critical competency. College \& undergraduate libraries, 22(1), 97-106.

Sinair, E., Ray, R.L., \& Canwell, A.L. (2018, October 25). HR Leaders Need Stronger Data Skills. Harvard Business Review. Retrieved from https://hbr.org/2018/10/hr-leaders-needstronger-data-skills

Stokes, S. (2001) Visual literacy in teaching and learning: a literature perspective. Electronic Journal for the Integration of Technology in Education, 1(1), pp. 10-19.

Strauss, K. (2016, May 17). These Are The Skills Bosses Say New College Grads Do Not Have. Forbes. Retrieved from https://www.forbes.com/sites/karstenstrauss/2016/05/17/these-are-theskills-bosses-say-new-college-grads-do-not-have/\#203528685491

Verma, I. M. (2014). Editorial expression of concern: experimental evidence of massive-scale emotional contagion through social networks. Proceedings of the National Academy of Sciences of the United States of America, 111(29), 10779-10779.

Whittaker, Z. (2019a, January). Millions of bank loan and mortgage documents have leaked online. TechCrunch. Retrieved from https://techcrunch.com/2019/01/23/financial-files/

Whittaker, Z. (2019b, May). Millions of Instagram influencers had their contact data scraped and exposed. TechCrunch. Retrieved from https://techcrunch.com/2019/05/20/instagram-influencercelebrity-accounts-scraped/

Wilder, C. R., \& Ozgur, C. O. (2015). Business analytics curriculum for undergraduate majors. INFORMS Transactions on Education, 15(2), 180-187.

Winterberry Group. (2018, February). The Data-Centric Organization 2018. (A Winterberry Group Research Report). Retrieved from https://www.iab.com/wpcontent/uploads/2018/02/DMA-IAB-Winterberry-Group-The-Data-Centric-Org-2018-February2018.pdf

Wolff, A., Gooch, D., Montaner, J. J. C., Rashid, U., \& Kortuem, G. (2016). Creating an understanding of data literacy for a data-driven society. The Journal of Community Informatics, 12(3).

Wright, S., Carlson, J., Jeffryes, J., Andrews, C., Bracke, M., Fosmire, M., . . Westra, B. (2015). Developing Data Information Literacy Programs: A Guide for Academic Librarians. In Carlson J. \& Johnston L. (Eds.), Data Information Literacy: Librarians, Data, and the Education of a New Generation of Researchers (pp. 205-230). West Lafayette, Indiana: Purdue University Press. Retrieved from http://www.jstor.org.unh.idm.oclc.org/stable/j.ctt6wq2vh.14

Zilinski, L., Sapp Nelson, M. R., \& Van Epps, A. S. (2014). Developing professional skills in STEM students: Data information literacy. Issues in Science and Technology Librarianship. 
Table I: Comparison of four extant data literacy competency frameworks

\begin{tabular}{|c|c|c|c|c|}
\hline $\begin{array}{l}\text { Authors } \\
\text { (publication } \\
\text { date) }\end{array}$ & Carlson et al. (2011) & Schneider (2013) & $\begin{array}{l}\text { Calzada Prado \&. Marzal } \\
\text { (2013). }\end{array}$ & Risdale, et al. (2015) \\
\hline Literacy & Data Information Literacy & Research Data Literacy & Data Literacy & Data Literacy \\
\hline Definition & $\begin{array}{l}\text { Understanding what data mean, } \\
\text { including how to read graphs and } \\
\text { charts appropriately, draw correct } \\
\text { conclusions from data, and } \\
\text { recognize when data are being used } \\
\text { in misleading or inappropriate } \\
\text { ways. }\end{array}$ & $\begin{array}{l}\text { A new sub-discipline within research } \\
\text { data management that emerges from the } \\
\text { need to educate students and scientists } \\
\text { of all disciplines and to train } \\
\text { information scientists from library and } \\
\text { information science to do so. }\end{array}$ & $\begin{array}{l}\text { The component of } \\
\text { information literacy that } \\
\text { enables individuals to access, } \\
\text { interpret, critically assess, } \\
\text { manage, handle and ethically } \\
\text { use data }\end{array}$ & $\begin{array}{l}\text { Ability to collect, manage, } \\
\text { evaluate, and apply data in a } \\
\text { critical manner }\end{array}$ \\
\hline Methodology & $\begin{array}{l}\text { Used faculty interviews, student } \\
\text { assessments, and a deep reading of } \\
\text { the Information Literacy } \\
\text { Competency Standards }\end{array}$ & $\begin{array}{l}\text { Merged the Information Literacy } \\
\text { Competency Standards with the Digital } \\
\text { Preservation Outreach and Education } \\
\text { Model curriculum then mapped to data } \\
\text { management skills }\end{array}$ & $\begin{array}{l}\text { Mapped competencies from } \\
\text { previous related work to the } \\
\text { Information Literacy } \\
\text { Competency Standards. }\end{array}$ & $\begin{array}{l}\text { Conducted a comprehensive } \\
\text { review of the literature and } \\
\text { synthesized the findings into a } \\
\text { data literacy matrix }\end{array}$ \\
\hline $\begin{array}{l}\text { Core } \\
\text { Competencies }\end{array}$ & $\begin{array}{l}\text { - Databases and data formats } \\
\text { - } \\
\text { Discovery and acquisition } \\
\text { organization } \\
\text { - } \text { Data conversion and } \\
\text { interoperability } \\
\text { - } \text { Quality assurance } \\
\text { - } \text { Detadata } \\
\text { - } \text { Cultures of practice } \\
\text { - Data preservation } \\
\text { - Data analysis } \\
\text { - } \text { Data visualization and } \\
\text { representation } \\
\text { Ethics, including citation of } \\
\text { data }\end{array}$ & $\begin{array}{l}\text { - Identify } \\
\text { - Scope } \\
\text { - Plan } \\
\text { - Store } \\
\text { - Protect } \\
\text { - Evaluate } \\
\text { - Manage } \\
\text { - Provide }\end{array}$ & $\begin{array}{l}\text { - Understanding data } \\
\text { - } \quad \text { Finding and/or obtaining } \\
\text { data } \\
\text { - Reading, interpreting, } \\
\text { and evaluating data } \\
\text { - Managing data } \\
\text { - Using data }\end{array}$ & $\begin{array}{ll}\text { - } & \text { Data discovery and } \\
& \text { collection } \\
\text { - } & \text { Evaluating and ensuring } \\
& \text { quality of data sources } \\
\text { - } & \text { Data organization } \\
\text { - } & \text { Data manipulation } \\
\text { - } & \text { Basic data analysis } \\
\text { - } & \text { Data interpretation } \\
\text { (understanding data) } \\
\text { - Identifying problems using } \\
\text { - } \text { data } \\
\text { - } \text { Pata visualization } \\
\text { - Data driven decision making } \\
\text { - Data citation } \\
\text { - Data sharing }\end{array}$ \\
\hline
\end{tabular}

